\title{
Cutting-Edge Forward Burn Nutrition: from the Battlefield to the Burn Center
}

\author{
Beth A. Shields ${ }^{1} \cdot$ Booker T. King ${ }^{1} \cdot$ Evan M. Renz ${ }^{2}$
}

Published online: 25 April 2016

(C) Springer International Publishing AG 2016

\begin{abstract}
The US Army Institute of Surgical Research (USAISR) Burn Center is among the first and largest burn centers in the world and is the only US military burn center. This American Burn Association-verified facility is located on the Fort Sam Houston military base, in San Antonio, TX. It has provided comprehensive burn care to both military personnel and civilians in the South Texas area since the end of World War II. The global mission of the USAISR is to optimize combat casualty care, including care for major thermal injuries. This optimization of combat casualty care is executed clinically in the USAISR Burn Center through interdisciplinary teamwork and by advancing the care provided based on leading edge
\end{abstract}

This article is part of the Topical Collection on The Military Perspective

The opinions or assertions contained herein are the private views of the author and are not to be construed as official or as reflecting the views of the Department of the Army or the Department of Defense. This article does not contain any studies with human or animal subjects performed by any of the authors.

Electronic supplementary material The online version of this article (doi:10.1007/s40719-016-0044-0) contains supplementary material, which is available to authorized users.

Booker T. King

booker.t.king.mil@mail.mil

Beth A. Shields

beth.a.shields6.civ@mail.mil

Evan M. Renz

evan.m.renz.mil@mail.mil

1 Nutritional Medicine \& Metabolism, USAISR Burn Center, 3698 Chambers Pass STE B, JBSA FT Sam Houston, Houston, TX 78234-7767, USA

2 Brooke Army Medical Center, 3551 Roger Brooke Drive, JBSA Ft Sam Houston, Houston, TX 78234-7767, USA research. This article focuses on clinical lessons learned in the area of burn nutrition over the last decade at this facility during the support of the combat casualties from Operation Iraqi Freedom and Operation Enduring Freedom; it also provides a review of current evidence-based nutritional medicine practices for treating patients with thermal injuries. The extreme nutritional demand and metabolic changes associated with severe burns have been well described. This hypermetabolic, hypercatabolic response can lead to lean body mass and strength loss, resulting in the lack of ability to perform activities of daily living, as well as infection, wound healing failure, and death. Nutrition is an essential tool to avoid these catastrophic results, but monitoring the nutrition status is complicated by the whole body volume overload, resulting from the initial massive fluid resuscitation, which is required to prevent cardiovascular collapse. Techniques such as estimating weight loss from the caloric deficit must be utilized in place of actual weight loss until the interstitial fluid is reclaimed and a dry weight is achieved. Replenishing the extreme caloric expenditure and nitrogen loss is challenging; hence, careful monitoring of the nutrition intake is an essential component of burn treatment. In addition, there are a number of potential adverse effects of nutritional therapy that must also be factored into the complex decision-making regarding the initiation and delivery of nutrition in the critically ill burn population.

Keywords Nutrition and trauma · Burn nutrition · Thermal injuries $\cdot$ Burn care $\cdot$ Enteral nutrition $\cdot$ Parenteral nutrition . Hypermetabolism

\section{Clinical Case}

A 22-year-old Army soldier was on patrol at a busy market in southern Afghanistan when an Afghani female detonated an 
explosive vest she was wearing underneath her clothing. Several soldiers were injured, but this soldier received the most severe injuries: $60 \%$ total body surface area (TBSA) burn, partial traumatic amputations of his bilateral lower extremities, a penetrating abdominal injury with evisceration of intra-abdominal contents, and a traumatic brain injury. Tourniquets were placed above the injuries to his lower extremities, a sternal interosseous infusion device was placed, and two liters of crystalloid were infused. The patient was expeditiously transported to a Combat Support Hospital where he was intubated, and central venous and arterial lines were placed. After transfusion of blood products, the fluid resuscitation was started in accordance with the USAISR "Rule of Tens" formula [1]. He was taken to the operating room where the amputations were completed to his lower extremities (wounds were left open), an exploratory laparotomy was performed with a small bowel resection, and a negative pressure wound device for temporary abdominal coverage was placed. He was transported by the Air Force Critical Care Air Transport Team from Afghanistan to Landstuhl Regional Medical Center in Germany several hours later. The fluid resuscitation was completed shortly after arrival to Germany. In Germany, the lower extremity and abdominal wounds were irrigated, a jejunostomy feeding tube was placed, and the abdomen was closed. The US Army Burn Flight Team changed the burn wound dressings, performed a superficial burn wound debridement, and then transported the patient via military aircraft from Germany to the USAISR Burn Center in San Antonio, TX. Enteral feeding was started via the jejunostomy tube shortly after arrival, and he was taken to the operating room the next day for burn wound excision and allograft placement.

\section{Introduction}

Severe thermal injury results in a significant hypermetabolic and catabolic response, but the first hours after injury are characterized by a hypodynamic response, known as the "Ebb" phase, mostly due to systemically circulating cardiodepressants [2]. This initial hypodynamic response quickly yields to a hyperdynamic systemic inflammatory response syndrome (SIRS), known as the "Flow" phase, resulting in hypermetabolism in magnitude and duration that is unmatched in any other patient population (Fig. 1) and that characteristically involves multiple organ systems [5•]. This SIRS response following thermal injury promotes the liberation of catecholamines, cortisol, acute phase reactants, and proinflammatory cytokines; these result in the elevation of heart rate and core body temperature and the conversion of amino acids to glucose (gluconeogenesis). Hyperglycemia with insulin resistance also follows. If nutrition is not appropriately initiated and adequately maintained during this period, the

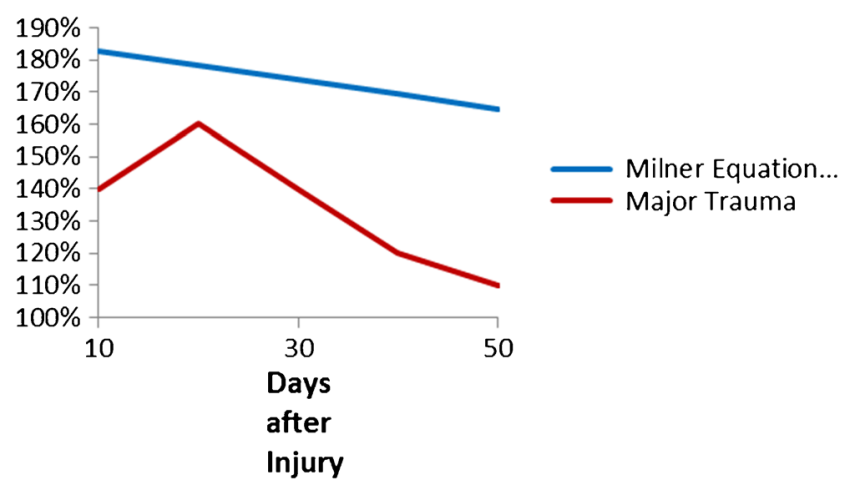

Fig. 1 Long et al. data for non-burn trauma vs. Milner equation for burn showing increased metabolic and catabolic rates [3, 4•]

result is poor wound healing, infection, sepsis, multi-organ dysfunction syndrome, and eventually death. Calories and protein must be supplied at greater than "normal" levels, often in quantities that significantly surpass that of other patients with major traumatic injuries $[5 \cdot 6]$.

\section{Fluid Resuscitation and Electrolyte Management}

In addition to the metabolic responses to burn, there is a marked increase in capillary permeability, commonly termed "capillary leak," resulting in loss of fluid into the interstitium. These losses are compounded by wound transudate and evaporative losses. All of these losses must be replaced by continuous intravenous (IV) infusion to prevent cardiovascular collapse [7]. For patients who weigh 40-80 kg, Lactated Ringer's is initiated using the USAISR "Rule of Tens" formula [1]: $10 \mathrm{~mL} / \mathrm{h}$ multiplied by the \%TBSA burn (Ex: $70 \%$ TBSA $=>$ initial IV fluid rate of $700 \mathrm{~mL} / \mathrm{h}$ ). This rate can then be adjusted by computerized decision support software or by 20 $25 \%$ each hour to achieve urine output goal range of 30 $50 \mathrm{ml} / \mathrm{h}$. Fluid resuscitation is discussed in further detail in the Joint Theater Trauma System (JTTS) Burn Clinical Practice Guidelines (CPGs). The fluid resuscitation can last $24 \mathrm{~h}$ or more, when capillary membranes regain their normal permeability [7]. As the enteral nutrition (EN) or oral intake advances, IV fluids are minimized as the patient is able to tolerate in an effort to reclaim the interstitial fluid. The gastrointestinal (GI) tract is primarily utilized for achieving calorie and protein goals, rather than correcting the large free water deficits that can occur even after the initial resuscitation period. This fluid lost through the open wounds can lead to severe hypernatremia, which requires IV fluid (5\% dextrose) for correction [8]. A rule of thumb for estimating the fluid lost through open wounds ( $\mathrm{mL} /$ day) is the body weight $(\mathrm{kg})$ multiplied by the \%TBSA open wounds (Ex: $70 \mathrm{~kg}, 70 \%$ TBSA open wound $=>4900 \mathrm{~mL} /$ day), but until all of the edema resolves, the clinical goal stands: minimize IV fluids as much as the patient can tolerate in order reclaim the interstitial fluid. 
As the wounds heal and fluid losses decrease, extreme thirst continues and hyponatremia becomes the predominant abnormality due to fluid overload, indicating the need for fluid restriction rather than sodium supplementation.

\section{Initial Nutrition Assessment}

The nutrition assessment includes: pre-injury dry weight; height; nutritional, medical, and surgical histories along with current status; medications; biochemical data; and physical examination $[9 \cdot \bullet]$. The pre-injury dry weight is used in calculating the calorie goal; ideal body weight (IBW) can be used in calculating protein goals. Pre-existing malnutrition can be determined by recent significant unintentional weight loss $(>5 \%$ over 1 month, $>10 \%$ over 6 months), poor oral intake prior to injury, a low body mass index, or visible lean body mass wasting. Although serum albumin levels are predictive of overall poor outcomes, they are not useful in assessing nutrition status in the acute phase of any burn or trauma patient $[9 \bullet \bullet, 10]$.

If the patient is malnourished, severe electrolyte disturbances can be expected upon the initiation of nutrition, especially hypophosphatemia $[11 \bullet, 12]$. This hypophosphatemia can be resistant to replacement. If this resistance occurs, the EN rate should be decreased temporarily until the electrolyte profile normalizes. Electrolytes should be repleted aggressively, and new levels should be drawn after each replacement to determine the need for further repletion and the timing for increasing the EN to the goal rate $[9 \cdot \bullet, 13]$.

\section{Energy}

The Milner equation (Table 1) was recently verified at the USAISR Burn Center and is useful in determining resting energy expenditure in adult patients with $\geq 20 \%$ TBSA burns $[3,15]$. Indirect calorimetry is also utilized, as it is a more accurate method of determining resting energy expenditure $[9 \cdot \bullet]$. The resting energy expenditure is then multiplied by an activity factor of 1.4 in an effort to maintain weight, hopefully with preservation of lean body mass. Physical activity, medications, and environmental factors are implemented to ensure that the lean body mass retention is maximized [16-19]. Avoiding severe lean body mass loss is essential to prevent infection, poor wound healing, pressure ulcer development, pneumonia, and death. The goal for the entire hospital stay is to maintain less than $10 \%$ weight loss from the preinjury dry weight. The initial fluid resuscitation frequently results in extreme edema; dry weight is commonly only achieved again when the wounds are healed. Therefore, caloric balance is monitored closely to estimate weight loss until a dry weight is achieved.
Table 1 Estimation of resting energy expenditure using the Milner Eq. 13

Milner equation (for patients with $\geq 20 \%$ TBSA burn)

$[\mathrm{BMR} \times(0.274+0.0079 \times \mathrm{TBSA}-0.004 \times \mathrm{PBD})+\mathrm{BMR}] \times 24 \times \mathrm{BS}-$ $\mathrm{A} \times \mathrm{AF}$

$\mathrm{EER}=$ Estimated energy requirement

TBSA $=$ Total body surface area burned $(\%) \times 100$, Ex: $20 \%$ burn, enter " 20 "

TBSA does not change with healing; always use the actual initial burn size, no maximum.

$\operatorname{BSA}\left(\mathrm{m}^{2}\right)$ (usual answers: $\left.1.5-2.5\right)=$ square $\operatorname{root}$ of; $(\mathrm{HT} \times \mathrm{WT}) / 3600$

$\mathrm{HT}=$ height $(\mathrm{cm})$

$\mathrm{WT}=$ weight $(\mathrm{kg})$ (for obese patients, use actual dry weight)

$\mathrm{AF}=$ Activity factor (typically 1.4 for weight maintenance, 1.0 when paralyzed)

PBD $=$ post-burn day

Male $\mathrm{BMR}=54.337821-(1.19961 \times \mathrm{Age})+\left(0.02548 \times \mathrm{Age}^{2}\right)-$ $\left(0.00018 \times \mathrm{Age}^{3}\right)$

Female BMR $=54.74942-(1.54884 \times$ Age $)+\left(0.03580 \times \mathrm{Age}^{2}\right)-$ $\left(0.00026 \times \mathrm{Age}^{3}\right)$

Note: BMR units are $\mathrm{kcal} / \mathrm{m}^{2} / \mathrm{h}[14]$

The estimated resting energy expenditure is not decreased below the initial level calculated with the Milner equation on the day of injury until $<10 \%$ TBSA open wound is achieved, then a new level can be determined with the Milner equation, which includes the number of days post-injury to account for the decrease in metabolism over time. This decrease in metabolism can take 1-2 years after full healing has occurred to return to normal.

\section{Protein}

The initial daily protein goal is calculated by multiplying the IBW [20] $(\mathrm{kg})$ by the grams of protein per $\mathrm{kg}$ IBW for the corresponding burn sizes shown in Fig. $2[4 \cdot, 9 \bullet \bullet, 21]$. This was adapted from urinary nitrogen loss data by Long et al. [4•] and Kagan et al. [21] An alternative method is to provide 20$25 \%$ of the caloric goal from protein, as this range has been found to be associated with improved outcomes, including a decreased number of days with bacteremia and decreased mortality $[22 \bullet \bullet]$.

In order to meet protein goals earlier, boluses of protein powder mixed in water are given every $3 \mathrm{~h}$ during the initiation of EN. As the EN rate is increased, this protein supplementation is decreased to maintain the protein goal shown in Fig. 2 or increased to achieve a positive nitrogen balance using the equation shown in Table 2. All urine output is collected each day to determine the urine urea nitrogen (UUN) or the total urea nitrogen (TUN) [9••]. UUN is more readily available than TUN and can be multiplied by a factor of 1.2 to estimate 
Fig. 2 Estimation of initial protein goals based on burn size $[17,18]$
Initial protein goals:

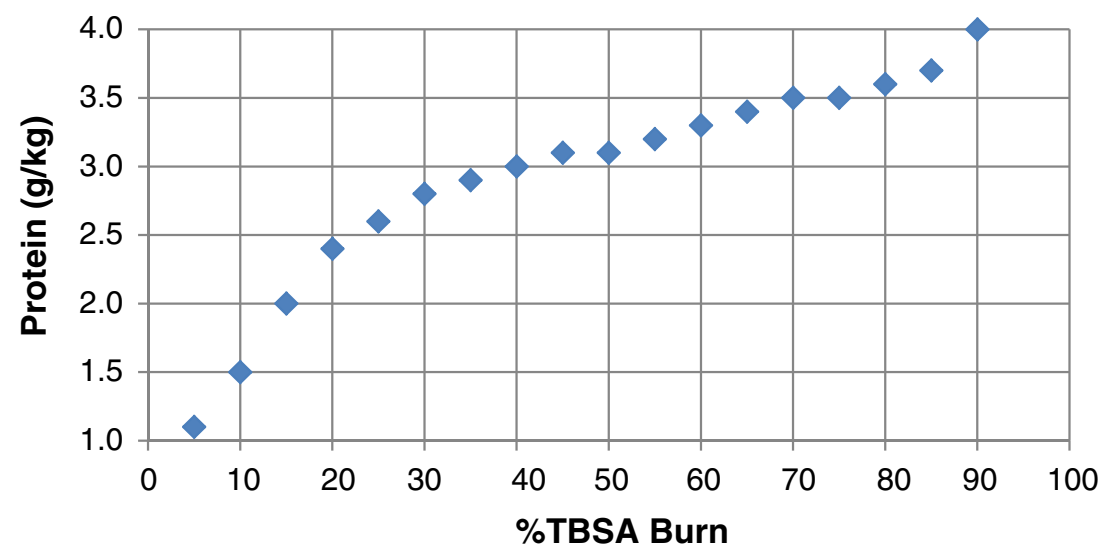

the TUN. Nitrogen is also lost through the transudate and/or exudate from the open wounds. The Waxman equation [23] estimates nitrogen losses through the open wounds. Open wound size is defined as the \%TBSA wound that is still weeping, including all unhealed donor sites. The goal is to achieve a positive nitrogen balance (keeping $<5 \mathrm{~g}$ protein $/ \mathrm{kg}$ IBW). The protein goal is not decreased below the initial estimate from Fig. 2 or $20-25 \%$ of the caloric goal until approximately hospital day 14, as UUNs have been found to increase during this time. Nitrogen balance studies are inaccurate in patients with poor renal function and, therefore, cannot be utilized during those times to estimate protein goals. Visceral protein (prealbumin, transferrin, retinol binding protein, etc.) levels are not helpful, as they are poor indicators of nutrition status $[9 \bullet \bullet, 10,24]$.

When transitioning from EN to oral intake alone (only when $<10 \%$ TBSA open wounds), the protein goal is decreased, but ensuring at least $1.5 \mathrm{~g}$ protein $/ \mathrm{kg}$ IBW is achieved with oral intake.

Table 2 Nitrogen balance equation including wound losses

Nitrogen balance $=$ Nitrogen intake - Nitrogen losses
Nitrogen intake $=$ gm protein intake 6.25
Nitrogen losses $=\mathrm{TUN}+2+$ Waxman
Waxman equations: $[23]$
Daily nitrogen loss, g, $1^{\text {st }}$ week $=0.3 \times$ BSA $\times \%$ TBSA Open Wound
Daily nitrogen loss, g, after $1^{\text {st }}$ week $=0.1 \times$ BSA $\times \%$ TBSA Open
Wound
$\%$ TBSA Open Wound $=$ Total body surface area open burn wound and
total body surface area unhealed donor sites $(\%) \times 100$, Ex: $20 \%$
burn $+20 \%$ unhealed donor, enter " 40 "
$\% \mathrm{TBSA}$ Open Wound does change with healing
BSA $\left(m^{2}\right)($ usual answers : $1.5-2.5)=$ square root of: $(H T \times W T) / 3600$
HT $=$ height $(\mathrm{cm})$
WT $=$ weight $(\mathrm{kg})$ (for obese patients, use actual dry weight)

\section{Fat vs. Carbohydrate}

Low-fat formulas (3-15\% of total calories) are associated with decreased pneumonia rates, sepsis, wound infections, length of hospitalization, and healing time for burned patients $[25,26 \bullet \bullet, 27 \bullet \bullet, 28 \bullet \bullet, 29 \bullet, 30]$. Specialty formulas for diabetes, renal failure, congestive heart failure, pulmonary failure, and acute respiratory distress syndrome should be avoided in burn patients because these formulas are all extremely high in fat content. Rather than switching to one of these high-fat specialty formulas, insulin can correct hyperglycemia and continuous renal replacement therapy can clear waste poor renal function.

\section{Parenteral Nutrition}

Patients who are at increased risk of malnutrition from the hypermetabolism and hypercatabolism following severe burns may be started on total parenteral nutrition (TPN) if their EN goals are not met within $48 \mathrm{~h}$ of admission. The use of early TPN in these patients with a high mortality risk and inability to tolerate EN goals is advocated at this burn center, but the practice in general remains controversial. For low mortality risk patients with a good nutritional status prior to injury, TPN can be initiated after 7 days of inability to tolerate EN $[9 \cdot \bullet, 31 \bullet \bullet]$.

Total caloric goals are not usually achieved with TPN, as the dextrose infusion rate is usually limited to $5 \mathrm{mg} / \mathrm{kg} / \mathrm{min}$ and lipids are not given unless the patient has not received any fat from EN or lipid-based medications for a full week [9••, $32,33]$. At that time, $500 \mathrm{kcal}$ of lipids is given only $2-3$ times per week to avoid continuous infusion of pro-inflammatory lipids, as well as to minimize fat intake for reasons already discussed. When giving IV lipid-based medication (propofol), triglyceride levels should be checked weekly. Liver function tests are monitored each week and renal function and 
electrolyte panels are monitored at least daily while initiating TPN. It is important to transition to full EN as soon as possible, as TPN has been associated with increased infection and mortality rates [9••, 34]. However, with modern critical care practices that have significantly reduced the incidence of infections classically associated with TPN (such as catheterrelated sepsis and pneumonias), multiple recent controlled trials have found little to no increased risk with TPN use. Although the rule of "use the gut" when at all possible should still be followed, a more liberalized approach to TPN use in the patient with a contraindication or intolerance to $\mathrm{EN}$ is becoming widely accepted $[9 \bullet \bullet, 31 \bullet \bullet]$.

\section{Enteral Nutrition}

EN should be initiated within the first $24 \mathrm{~h}$ of admission, as this has been shown to be safe and has been found to be associated with decreased time in the intensive care unit and decreased wound infection rates [9••, 35, 36•, 37, 38•]. Bowel sounds, stool output, and flatus have not been found to be associated with bowel function and should not be a barrier to initiating $\mathrm{EN}[9 \bullet \bullet]$. EN is initiated in the hemodynamically stable patient in which the base deficit and lactate levels are normalizing [9••]. The initial EN rate is $20 \mathrm{ml} / \mathrm{h}$ and is increased by $20 \mathrm{ml} / \mathrm{h}$ every $4 \mathrm{~h}$ until the target rate is achieved [39]. The goal is to reach the hourly target feeding rate within $48 \mathrm{~h}$ of admission and thereafter meet $100 \pm 20 \%$ of calorie goal every day starting on hospital day $3[9 \bullet \bullet, 40]$. Wound healing and minimizing lean body mass loss are the primary goals of this aggressive nutritional regimen.

\section{Interruptions in Enteral Nutrition}

EN is the preferred method of feeding, but frequent interruptions are common and can lead to severe weight loss. The EN rate can be increased to compensate for these interruptions. One strategy is to increase the current hourly goal rate by $1 / 6$ for $6 \mathrm{~h}$ for every $1 \mathrm{~h}$ of $\mathrm{EN}$ missed $[9 \bullet \bullet, 40]$. The historic practice of holding EN at midnight prior to surgery is not supported in the literature; gastric feeding can be withheld $4 \mathrm{~h}$ prior to surgery, and post-pyloric feeding can be held when the patient is transported to the operating room [9••]. The risk of perioperative aspiration is low using these guidelines, and some are advocating continuing post-pyloric feeding without interruption during extra-abdominal surgical procedures. EN can be resumed post-operatively at the hourly rate tolerated prior to surgery, provided the patient is otherwise hemodynamically stable [41].

$\mathrm{EN}$ is routinely held when epinephrine or norepinephrine is initiated; however, there appears to be no contraindication to maintaining EN when the patient is otherwise hemodynamically stable receiving either low-dose vasopressin or dobutamine. Gastric residuals are monitored every $4 \mathrm{~h}$ through the nasal gastric tube (NGT), but smaller caliber nasal enteric feeding tubes should not be used to check residuals. Residuals should be returned to the patient (up to $300 \mathrm{~mL}$ ). When residual amounts are $500 \mathrm{~mL}$ or more, $\mathrm{EN}$ is held for $2 \mathrm{~h}$. Therapies for treating elevated residuals include gastric promotility agents and post-pyloric dobhoff tube (DHT) placement [9••]. Utilizing both NGT (for decompression and gastric drainage) and post-pyloric DHT (for simultaneous feeding), EN can be continued as long as the gastric output does not reveal EN output.

\section{Monitoring Nutrition Intake}

Caloric intake from EN, TPN, IV fluid and oral intake is monitored closely until the patient has $<10 \%$ TBSA open wound and caloric goals are consistently being met. Caloric surpluses in excess of $120 \%$ of goal are avoided, as overfeeding can lead to hyperglycemia, ventilator dependence (from increased $\mathrm{CO}_{2}$ production), and fatty liver. Monitoring $\mathrm{CO}_{2}$ levels is, at times, useful in determining if the patient is being overfed. When hypercarbia develops in the absence of pulmonary dysfunction, the EN rate can be decreased by approximately $20 \%$, but only when the patient has been achieving caloric goals consistently. If the $\mathrm{CO}_{2}$ level normalizes with this adjustment, the caloric goal is decreased. Confirmation with indirect calorimetry allows for the measurement of the metabolic rate and calculation of the respiratory quotient to better set the calorie goal.

\section{Oral Nutrition}

Transitioning from EN to oral intake prematurely can lead to serious caloric deficits. A regular diet should be started as soon as the patient can tolerate oral intake. We find no evidence to support a ritualistic slow, multistep progression to a normal diet from clear liquids, and this significantly prolongs the time to adequate oral nutrition intake [9••]. The patient's mental status is evaluated prior to the trial of oral intake. The patient must have clear cognition and be able to manage their own oral and pulmonary secretions. If the patient has both an NGT and a DHT, the NGT should be removed prior to the trial of oral intake to facilitate swallowing. Small amounts of pudding texture are given initially, as this is the easiest texture to swallow. This is followed by sips of supplement drink. Change in voice, coughing, decrease in oxygen saturation, and the appearance of the foods or beverages consumed in the tracheal secretions are all indications that the patient is not tolerating oral feeding. When the patient has no difficulty tolerating oral feeding, soft, bland foods are recommended for 
the first meal and chewing foods thoroughly is encouraged. Patients are often easily satiated and therefore have minimal solid food intake, but they are extremely thirsty, which aids in meeting calorie goals by drinking 8-24 supplement drinks per day [42]. Water, Gatorade ${ }^{\circledR}$, Kool-Aid ${ }^{\circledR}$, fruit juices, and sodas are not calorically dense enough to adequately support nutrition in the hypermetabolic state. The overactive thirst mechanism can lead to water intoxication (severe hyponatremia) if the patient is allowed to drink all the fluids desired. Fluid restriction is indicated to treat hyponatremia, but the patients must be allowed to meet nutritional goals. Therefore, liquid nutritional supplements should rarely be withheld. The fluid restriction is usually accomplished by providing only supplements and milk for oral fluids.

\section{Medications and Other Treatments for the Hypermetabolic Response after Thermal Injury}

Physical therapy aids in the retention of lean body mass, and many medications have been found to do the same. Insulin supports anabolism, and poor glucose control has been found to be associated with increased pulmonary and urinary infections in burn patients [43]. Insulin therapy can result in hypoglycemia if insulin protocols are too restrictive. IV insulin therapy is started with the goal of keeping the blood glucose less than $180 \mathrm{mg} / \mathrm{dL}$. Long-acting insulin is avoided in patients with normal hemoglobin A1c levels on admission in order to avoid hypoglycemia when the inflammatory state begins to abate.

Oxandrolone is an anabolic steroid that has been extensively studied in the burn population and has been shown to significantly increase lean body mass retention and decrease length of hospital stay [44••]. The dosing is $10 \mathrm{mg}$ twice each day and is started as early as post-burn day 5 . The only adverse outcome found in a multicenter trial was elevated alanine aminotransferase (ALT) levels; therefore, liver function tests are followed weekly, and oxandrolone is held for ALT over $200 \mathrm{U} / \mathrm{L}$.

In burned children, propranolol was found to reduce heart rate, metabolism, and protein catabolism and thereby increase lean body mass retention [45]. However, propranolol has not been studied extensively in the burned adult population. In our burn center, propranolol is usually started when the heart rate exceeds 120 beats per minute on or after post-burn day 5 in the absence of another obvious source for the tachycardia. The initial dosing is $10 \mathrm{mg}$ two or three times per day and titrated to a goal of decreasing the heart rate by $20 \%$. Hold parameters should be specified to prevent bradycardia and hypotension. An ongoing prospective, randomized trial on propanolol (the Propanolol Study) should provide evidence to better characterize the appropriate role of propanolol in adults with major thermal injury. Other important treatments to minimize the hypermetabolic response include treatment of pain, infection control, and keeping the room temperature at least $90{ }^{\circ} \mathrm{F}[46,47]$.

\section{Glutamine, Vitamin, and Mineral Supplementation}

Glutamine is a nutritional supplement which has been shown to decrease infection rates, improve wound healing, and decrease hospital length of stay for burn patients [48-51, 52•]. However, in non-burned patients with multi-system organ failure, glutamine supplementation has been found to be associated with increased mortality [53]. Therefore, the use of glutamine supplementation in the intensive care unit is a controversial practice. Enteral glutamine is given currently to patients with $\geq 20 \%$ TBSA burn except in cases of significant hepatic dysfunction or pre-existing kidney disease. The dosing is approximately $0.5 \mathrm{~g} / \mathrm{kg}$ IBW per day $(15 \mathrm{~g}$ packs mixed with water and given immediately as boluses, usually twice per day) and is started along with EN initiation. An ongoing prospective, randomized trial of enteral glutamine supplementation (the RE-ENERGIZE Study) should provide evidence to better characterize the appropriate role of glutamine supplementation after major thermal injury. Patients with $\geq 20 \%$ TBSA burn are also given a multivitamin, vitamin $\mathrm{C}$, zinc sulfate, thiamine, folic acid, vitamin $\mathrm{E}$, and selenium as daily supplements $[9 \cdot \bullet, 54,55 \cdot]$. Patients with smaller burns are given daily multivitamin and vitamin $\mathrm{C}$. Vitamins $\mathrm{C}$ and $\mathrm{E}$ are antioxidants and have distinct roles in wound healing. Selenium is another antioxidant and is given as a supplement in critically ill burn patients $[9 \bullet \bullet, 56]$. Patients with large burns have been found to be zinc-deficient; therefore, zinc supplementation can aid in wound healing. Thiamine and folic acid can help decrease lactic acid levels in patients with large burns. Vitamin or mineral deficiencies should be treated, although iron may be an exception. Iron is not commonly supplemented as patients often receive several blood products and have ferritin levels indicative of iron overload. Inappropriate iron supplementation has also been found to be associated with increased risk of infections. Sodium replacement should be avoided in cases of hyponatremia, as the cause of the hyponatremia is a free water excess rather than a sodium deficiency. After achieving $<10 \%$ TBSA open wounds, zinc, thiamine, folic acid, and vitamin $\mathrm{E}$ can be discontinued.

\section{Wound Healing}

When there is evidence of poor wound healing, copper and zinc levels should be evaluated to determine if there is a need for IV supplementation. Protein provisions are increased at this time (keeping $<6 \mathrm{~g}$ protein $/ \mathrm{kg}$ IBW), in a final attempt to aid in wound healing. Growth hormone is occasionally 
prescribed for these patients with wound healing failure in conjunction with IV insulin [57].

\section{Combat Casualty Burn Care}

Approximately 1000 combat casualties have been treated at the USAISR Burn Center since 2003. Most of these patients sustained injuries while conducting combat operations in Iraq or Afghanistan. Despite the long distances and logistical problems of evacuating casualties from a combat zone, most casualties arrived at our burn center within an average of $96 \mathrm{~h}$ following injury. Initial stabilization and fluid resuscitation occurred during the continuum of care at various medical facilities throughout the theater of operations during the long range evacuation. These patients were initially evacuated to Germany, where they were stabilized and then transported to the USAISR Burn Center in San Antonio, TX. Although enteral feeding tubes were often placed in patients with severe burns, EN was rarely initiated prior to arrival at the USAISR Burn Center. Enteral feeding was generally not performed during aeromedical transport due to the presumed increased risk of aspiration [58, 59].

Combat casualty burn care is complicated by many factors. Some of these factors include: multi-system traumatic injuries in addition to the thermal injury, austere locations of many of the medical facilities that provide care to combat wounded, limited medical equipment and resources at the medical facilities in combat zones, and medical providers with lack of experience and training in burn care. Burn CPGs were first developed in 2006 in an attempt to guide the front line medical providers through the complexities of combat casualty burn care and to improve patient outcomes (see Appendix A).

One area of combat casualty burn care that has been greatly impacted by the JTTS Burn CPGs is fluid resuscitation. In the early part of the conflicts in Iraq and Afghanistan, the fluid resuscitation given after thermal injury was not standardized and many different resuscitation formulas were being utilized. Many patients with larger burn sizes received excessive volumes of crystalloid. This "over-resuscitation" leads to the complications of extremity and abdominal compartment syndrome, increasing morbidity and mortality in this population [60]. The JTTS flowsheet was created to track the resuscitation of burn patients from point of injury to $72 \mathrm{~h}$ postinjury. The use of albumin, plasma, other colloids and vasopressors was recorded as well. The use of the JTTS flowsheet in conjunction with adherence to Burn CPGs was shown to significantly improve outcomes [61].

\section{Conclusions}

After severe thermal injury, the resting energy expenditure can double and protein losses can triple. Careful monitoring of the nutrition status is an important component of burn care. The large volumes required for fluid resuscitation mask some monitors of the nutritional status, so other methods, including estimation of weight loss from the calorie deficit, must be utilized in place of actual weight loss until the edema has resolved. Meeting the hypermetabolic response with appropriate nutrition support can avoid severe weight loss and the associated morbidities, including increased infection rates, decreased wound healing, pressure ulcer development, and pneumonia. Meeting the extreme calorie and protein goals with EN is challenging, as interruptions can occur frequently. Problem solving using enteral feeding practice guidelines as described in this article and close monitoring of nutritional intake is essential for the recovery of the burn patient $[9 \cdot \bullet]$.

\section{Compliance with Ethical Standards}

Conflict of Interest Ms. Shields has patents pending, Nutrition Decision Support System, ISR 13-17, System and Method for Automated Measuring and Processing of Gastric Residuals, ISR 13-40, Improved Nasogastric Tube System for Improved Tolerance Monitoring, ISR 14-02, and reports that TheraNova is applying to license this technology. Drs. King and Renz declare no conflicts of interest.

Human and Animal Rights and Informed Consent This article does not contain any studies with human or animal subjects performed by any of the authors

\section{References}

Papers of particular interest, published recently, have been highlighted as:

- Of importance

- Of major importance

1. Chung KK, Salinas J, Renz EM, et al. Simple derivation of the initial fluid rate for the resuscitation of severely burned adult combat casualties: in silico validation of the rule of 10 . J Trauma. 2010;69 Suppl 1:S49-54.

2. Latenser BA. Critical care of the burn patient: the first 48 hours. Crit Care Med. 2009;37(10):2819-26.

3. Milner EA, Cioffi WG, Mason AD, et al. A longitudinal study of resting energy expenditure in thermally injured patients. J Trauma. 1994;37(2):167-70.

4. Long CL, Schaffel N, Geiger JW, et al. Metabolic response to injury and illness: estimation of energy and protein needs from indirect calorimetry and nitrogen balance. JPEN. 1979;3(6):452-6. This classic study showed the difference in peak and duration of hypermetabolism and catabolism after burn vs. other trauma. 
5. Williams FN, Jeschke MG, Chinkes DL, et al. Modulation of the hypermetabolic response to trauma: temperature, nutrition, and drugs. J Am Coll Surg. 2009;208(4):489-502. Excellent review of methods to minimize the hypermetabolic response to injury and improve anabolism.

6. Jeschke MG, Chinkes DL, Finnerty CC, et al. Pathophysiologic response to severe burn injury. Ann Surg. 2008;248(3):387-401.

7. Warden GD. Burn shock resuscitation. World J Surg. 1992;16(1):16-23.

8. Hinton P, Allison SP, Littlejohn S, Lloyd J. Electrolytes changes after burn injury and effect of treatment. Lancet. 1973;4(7823): 218-21.

9.• McClave SA, Taylor BE, Martindale RG, et al. Guidelines for the provision and assessment of nutrition support therapy in the adult critically ill patient: Society of Critical Care Medicine (SCCM) and American Society for Parenteral and Enteral Nutrition (A.S.P.E.N.). JPEN. 2016;40(2):159-211. New ASPEN/SCCM guidelines for critically ill patients.

10. Carlson DE, Cioffi Jr WG, Mason Jr AD, et al. Evaluation of serum visceral protein levels as indicators of nitrogen balance in thermally injured patients. JPEN. 1991;15(4):440-4.

11. Kahn SA, Bell DE, Stassen NA, Lentz CW. Prevention of hypophosphatemia after burn injury with a protocol for continuous, preemptive repletion. J Burn Care Res. 2015;36(3):e220-5. This article compares a more aggressive IV phosphorus replacement protocol to an historical control, which decreased the incidence of hypophosphatemia, along with a significantly lower rate of cardiac and infectious complications.

12. Berger MM, Rothen C, Cavadini C, Chiolero RL. Exudative mineral losses after serious burns: a clue to the alterations of magnesium and phosphate metabolism. Am J Clin Nutr. 1997;65(5):1473-81.

13. Marinella MA. The refeeding syndrome and hypophosphatemia. Nutr Rev. 2003;61(9):320-3.

14. Fleisch A. Basal metabolism standard and its determination with the “metabolocalculator". Helv Med Acta. 1951;18(1):23-44.

15. Shields BA, Doty KA, Chung KK, et al. Determination of resting energy expenditure after severe burn. J Burn Care Res. 2013;34(1): e22-8.

16. Graves C, Saffle J, Cochran A. Actual burn nutrition care practices: an update. J Burn Care Res. 2009;30(1):77-82.

17. Hart DW, Wolf SE, Herndon DN, et al. Energy expenditure and caloric balance after burn: increased feeding leads to fat rather than lean mass accretion. Ann Surg. 2002;235(1):152-61.

18. Goran MI, Peters EJ, Herndon DN, Wolfe RR. Total energy expenditure in burned children using the doubly labeled water technique. Am J Physiol. 1990;259(4 Pt 1):E576-85.

19. Garrel DR, de Jonge L. Thermogenic response to feeding in severely burned patients: relation to resting metabolic rate. Burns. 1993;19(6):467-72.

20. Hamwi GJ. Therapy: changing dietary concepts. In: Danowski TS, editor. Diabetes Mellitus: Diagnosis and Treatment (vol 1). New York: American Diabetes Association; 1964. p. 73-8.

21. Kagan RJ, Matsuda T, Hanumadass M, et al. The effect of burn wound size on ureagenesis and nitrogen balance. Ann Surg. 1982;195(1):70-4.

22.• Alexander JW, MacMillan BG, Stinnett JD, et al. Beneficial effects of aggressive protein feeding in severely burned children. Ann Surg. 1980;192(4):505-17. Prospective, randomized controlled study showing significantly lower number of days with bacteremia and lower mortality with higher protein provisions.

23. Waxman K, Rebello T, Pinderski L, et al. Protein loss across burn wounds. J Trauma. 1987;27(2):136-40.

24. Shields BA, Pidcoke HF, Chung KK, et al. Are visceral proteins valid markers for nutritional status in the burn intensive care unit? J Burn Care Res. 2015;36(3):375-80.
25. Wolf SE, Shields BA, Wade CE. Substrate utilization in the critically ill. JPEN. 2009;33(1):111.

26.• Hart DW, Wolf SE, Zhang XJ, et al. Efficacy of a high-carbohydrate diet in catabolic illness. Crit Care Med. 2001;29(7):1318-24. Prospective, randomized, crossover trial evaluating carbohydrate vs. fat utilization following thermal injury. Found improved protein balance with high carbohydrate, very low fat (3\%) enteral nutrition.

27.• Garrel DR, Razi M, Larivière F, et al. Improved clinical status and length of care with low-fat nutrition support in burn patients. JPEN. 1995;19(6):482-91. Prospective, randomized, controlled trial evaluating types and amounts of fat following thermal injury. Found lower infection rates and decreased length of hospital stay with low fat $(\mathbf{1 5 \%})$ enteral nutrition and no benefit to different types of fat.

28.• Gottschlich MM, Jenkins M, Warden GD, et al. Differential effects of three enteral dietary regimens on selected outcomes variables in burn patients. JPEN. 1990;14(3):225-36. Prospective, randomized, blinded trial evaluating low, standard, and high fat enteral nutrition following thermal injury. Found lower wound infection rates and decreased length of hospital stay normalized for \% TBSA burn with low fat (12\%) enteral nutrition.

29. Lee JO, Gauglitz GG, Herndon DN, et al. Association between dietary fat content and outcomes in pediatric burn patients. J Surg Res. 2011;166(1):e83-90. Retrospective cohort study evaluating low and high fat enteral nutrition following thermal injury. Found lower sepsis rates and decreased length of hospital stay and less fatty liver with low fat $(3 \%)$ enteral nutrition.

30. Masters B, Aarabi S, Sidhwa F, Wood F. High-carbohydrate, highprotein, low-fat versus low-carbohydrate, high-protein, high-fat enteral feeds for burns. Cochrane Database Syst Rev 2012, Issue 1. Art. No.: CD006122. doi: 10.1002/14651858.CD006122.pub3.

$31 . \bullet$ Wischmeyer P. Parenteral nutrition and calorie delivery in the ICU: controversy, clarity, or call to action? Curr Opin Crit Care. 2012;18(2):164-73. Excellent review article evaluating recent prospective, randomized, controlled trials on early parenteral nutrition.

32. Canadian Clinical Practice Guidelines May 2015: Canadian Clinical Practice Guidelines: Strategies to Optimize Parenteral Nutrition and Minimize Risks: Use of lipids. http:// criticalcarenutrition.com/docs/CPGs\%202015/10.2\%202015.pdf.

33. Canadian Clinical Practice Guidelines May 2015: Canadian Clinical Practice Guidelines: strategies to optimize parenteral nutrition and minimize risks: Dose of PN. http://criticalcarenutrition. com/docs/CPGs\%202015/10.1\%202015.pdf

34. Herndon DN, Barrow RE, Stein M, et al. Increased mortality with intravenous supplemental feeding in severely burned patients. J Burn Care Res. 1989;10(4):309-13.

35. Chiarelli A, Enzi G, Casadei A, et al. Very early nutrition supplementation in burned patients. Am J Clin Nutr. 1990;51(6):1035-9.

36. Mosier MJ, Pham TN, Klein MB, et al. Early enteral nutrition in burns: compliance with guidelines and associated outcomes in a multicenter study. J Burn Care Res. 2011;32(1):104-9. Descriptive multicenter study from the Glue Grant on over 150 subjects reporting lower wound infection rates and decreased length of intensive care unit stay when starting enteral nutrition within 24 hours of admission.

37. Enzi G, Casadei A, Sergi G, et al. Metabolic and hormonal effects of early nutritional supplementation after surgery in burn patients. Crit Care Med. 1990;18(7):719-21.

38. McDonald WS, Sharp Jr CW, Deitch EA. Immediate enteral feeding in burn patients is safe and effective. Ann Surg. 1991;213(2):177-83. Descriptive study on over 100 subjects reporting on safety of starting enteral nutrition within 1 hour of admission. 
39. Kesey J, Dissanaike S. A protocol of early aggressive acceleration of tube feeding increases ileus without perceptible benefit in severely burned patients. J Burn Care Res. 2013;34(5):515-20.

40. Heyland DK, Cahill NE, Dhaliwal R, et al. Enhanced proteinenergy provision via the enteral route in critically ill patients: a single center feasibility trial of the PEP uP protocol. Crit Care. 2010;14(2):R78.

41. Shields BA, Brown JN, Aden JK, et al. A pilot review of gradual versus goal re-initiation of enteral nutrition after burn surgery in the hemodynamically stable patient. Burns. 2014;40(8):1587-92.

42. Wade CE, Mora AG, Shields BA, et al. Signals from fat after injury: plasma adipokines and ghrelin concentrations in the severely burned. Cytokine. 2013;61(1):78-83.

43. Hemmila MR, Taddonio MA, Arbabi S, et al. Intensive insulin therapy is associated with reduced infectious complications in burn patients. Surgery. 2008;144(4):629-37.

44.• Wolf SE, Edelman LS, Kemalyan N, et al. Effects of oxandrolone on outcomes measures in the severely burned: a multicenter prospective randomized double-blind trial. J Burn Care Res. 2006;27(2):131-9. Multicenter, prospective, randomized, controlled, double-blind study showing a $28 \%$ decrease in length of hospital stay with oxandrolone use.

45. Herndon DN, Hart DW, Wolf SE, et al. Reversal of catabolism by beta-blockade after severe burns. N Engl J Med. 2001;345(17): 1223-9.

46. Caldwell Jr FT, Wallace BH, Cone JB, Manuel L. Control of the hypermetabolic response to burn injury using environmental factors. Ann Surg. 1992;215(5):485-90.

47. Wilmore DW, Mason Jr AD, Johnson DW, Pruitt Jr BA. Effect of ambient temperature on heat production and heat loss in burn patients. J Appl Physiol. 1975;38(4):593-7.

48. Garrel D, Patenaude J, Nedelec B, et al. Decreased mortality and infectious morbidity in adult burn patients given enteral glutamine supplements: a prospective, controlled, randomized clinical trial. Crit Care Med. 2003;31(10):2444-9.

49. Peng X, Yan H, You Z, et al. Glutamine granule-supplemented enteral nutrition maintains immunological function in severely burned patients. Burns. 2006;32(5):589-93.

50. Wischmeyer PE, Lynch J, Liedel J, et al. Glutamine administration reduces Gram-negative bacteremia in severely burned patients: a prospective, randomized, double-blind trial versus isonitrogenous control. Crit Care Med. 2001;29(11):2075-80.

51. Lin JJ, Chung XJ, Yang CY, Lau HL. A meta-analysis of trials using the intention to treat principle for glutamine supplementation in critically ill patients with burn. Burns. 2013;39(4):565-70.

52. Czapran A, Headdon W, Deane AM, et al. International observational study of nutritional support in mechanically ventilated patients following burn injury. Burns. 2015;41:510-8. Multicenter survey of nutrition practices, showing that calorie and protein deficits were associated with increased mortality; calorie deficits were significantly lower when a gastric promotility agent was started prophylactically; glutamine use was associated with survival.

53. Heyland DK, Elke G, Cook D, et al. Glutamine and antioxidants in the critically ill patient: a post hoc analysis of a large-scale randomized trial. JPEN. 2015;39(4):401-9.

54. Prelack K, Sheridan RL. Micronutrient supplementation in the critically ill patient: strategies for clinical practice. J Trauma. 2001;51(3):601-20.

55. Nordlund MJ, Pham TN, Gibran NS. Micronutrients after burn injury: a review. J Burn Care Res. 2014;35(2):121-33. Excellent review article on micronutrient supplementation for burns.

56. Angstwurm MW, Engelmann L, Zimmermann T, et al. Selenium in Intensive Care (SIC): results of a prospective randomized, placebocontrolled, multiple-center study in patients with severe systemic inflammatory response syndrome, sepsis, and septic shock. Crit Care Med. 2007;35(1):118-26.

57. Gilpin DA, Barrow RE, Rutan RL, et al. Recombinant human growth hormone accelerates wound healing in children with large cutaneous burns. Ann Surg. 1994;220(1):19-24.

58. Renz EM, Cancio LC, Barillo DJ, et al. Long range transport of war-related burn casualties. J Trauma. 2008;64(2 Suppl):S136-45.

59. White CE, Renz EM. Advances in surgical care: management of severe burn injury. Crit Care Med. 2008;36(7 Suppl):S318-24.

60. Chung KK, Wolf SE, Cancio LC, et al. Resuscitation of severely burned military casualties: fluid begets more fluid. J Trauma. 2009;67(2):231-7.

61. Ennis JL, Chung KK, Renz EM, et al. Joint Theater Trauma System implementation of burn resuscitation guidelines improves outcomes in severely burned military casualties. J Trauma. 2008;64(2 Suppl): S146-51. 